Quim. Nova, Vol. 36, No. 8, 1236-1241, 2013

\title{
CONTEXTUALIZANDO REAÇÕES ÁCIDO-BASE DE ACORDO COM A TEORIA PROTÔNICA DE BRÖNSTED- LOWRY USANDO COMPRIMIDOS DE PROPRANOLOL E NIMESULIDA
}

\author{
Arlan de Assis Gonsalves*, Cleônia Roberta Melo Araújo, Carlos Alberto Leite Filho e Felipe Santana de Medeiros \\ Universidade Federal do Vale do São Francisco, Campus Petrolina Centro, 56304-917 Petrolina - PE, Brasil
}

Recebido em 26/9/12; aceito em 26/3/13; publicado na web em 14/5/13

\begin{abstract}
CONTEXTUALIZING ACID-BASE REACTIONS ACCORDING TO BRÖNSTED-LOWRY PROTONIC THEORY USING PROPRANOLOL AND NIMESULIDE TABLETS. This paper reports the use of alternative materials for teaching experimental chemistry. In this context, nimesulide and propranolol tablets were used to teach chemical concepts about acid-base reactions according to Brönsted-Lowry protonic Theory. Important topics of Organic, Analytical and Pharmaceutical Chemistry were discussed, such as purification by acid-base extraction, solubility of organic compounds in aqueous solutions, buffers, the dissociation constant $\left(\mathrm{pK}_{\mathrm{a}}\right)$, potentiometric titration and ionization of drugs in biological fluids. The purification of propranolol and nimesulide from tablets produced yields of $75 \%$ and $90 \%$, respectively. The experimental values of $\mathrm{pK}_{\mathrm{a}}$ for both drugs were in agreement with those from the literature.
\end{abstract}

Keywords: acid-base reactions; propranolol; nimesulide.

\section{INTRODUÇÃO}

A execução de aulas práticas no ensino superior é um recurso didático que aumenta a motivação dos estudantes, ensina habilidades manuais, contribui para uma melhor aprendizagem, possibilita a contextualização e a fixação de princípios teóricos ministrados em sala de aula e desenvolve atitudes requeridas para a realização de pesquisa científica. ${ }^{1-3}$

O uso de materiais alternativos e que fazem parte do cotidiano dos estudantes em aulas práticas de química é uma estratégia didático-pedagógica que vem sendo bastante empregada no ensino de química experimental. Diante desta tendência, o presente trabalho propõe a utilização de dois medicamentos amplamente prescritos no Brasil, comprimidos de propranolol e nimesulida, como materiais alternativos de aulas práticas de Química Orgânica, Analítica ou Farmacêutica.

As atividades propostas neste trabalho envolvem técnicas comumente ministradas em aulas práticas de química experimental, porém, o foco principal é ilustrar algumas aplicações das reações ácido-base fundamentando-se na teoria protônica de Brönsted-Lowry. Neste sentido, serão abordados os temas: extração ácido-base, soluções tampão, determinação de $\mathrm{pK}_{\mathrm{a}}$ de substâncias e importância deste parâmetro na absorção de fármacos pelo organismo. No presente trabalho são abordados diferentes conceitos teóricos, porém, os mesmos serão interligados de forma a permitir ao estudante assimilar gradativamente, e de maneira integrada, conteúdos teórico-práticos acerca de reações ácido-base.

Em razão da simplicidade dos experimentos que serão apresentados, estes podem ser facilmente executados em laboratórios de química de instituições de ensino superior na forma de aulas práticas para graduandos dos cursos de Farmácia, Química e Engenharia Química.

\section{Fundamentos Teóricos}

\section{Medicamentos utilizados nos experimentos}

O propranolol (Figura 1) é um fármaco da classe dos bloqueadores de receptores cardíacos $\beta$-adrenégicos prescrito para o tratamento de algumas doenças cardiovasculares tais como angina pectoris, hipertensão, arritmias cardíacas e infarto do miocárdio. ${ }^{4}$ Esta substância trata-se de um pó branco amorfo, inodoro e de sabor amargo, pouco

*e-mail: arlangonsalves@ hotmail.com solúvel em água, solúvel em etanol e em acetona e de ponto de fusão em torno de $96{ }^{\circ} \mathrm{C} .{ }^{5,6} \mathrm{Em}$ medicamentos este fármaco está na forma de cloridrato de propranolol, sendo solúvel em água e possuindo um ponto de fusão entre 163 e $164{ }^{\circ} \mathrm{C} .{ }^{6}$ As apresentações comercialmente disponíveis deste principio ativo são comprimidos e soluções injetáveis, mas neste trabalho serão utilizados apenas comprimidos de cloridrato de propranolol.

A nimesulida (Figura 1) é um fármaco anti-inflamatório não esteroide (AINE) prescrito no Brasil como anti-inflamatório, analgésico e antitérmico. ${ }^{7}$ A segurança do uso farmacológico de nimesulida tem sido amplamente discutida pelos países da União Europeia devido a inúmeros relatos de insuficiência hepática produzida pelo uso contínuo e prolongado deste fármaco. Apesar disto, a ANVISA ainda mantém a autorização para a comercialização deste anti-inflamatório no Brasil para crianças acima de 12 anos de idade. ${ }^{8}$ Esta substância é um pó amarelo pálido, inodoro, praticamente insolúvel em água, pouco solúvel em etanol e muito solúvel em acetona, ${ }^{5}$ com ponto de fusão em torno de $147^{\circ} \mathrm{C} .{ }^{9}$ As apresentações disponíveis deste principio ativo são comprimidos, suspensões orais, géis e supositórios, mas neste trabalho serão utilizados apenas comprimidos de nimesulida.

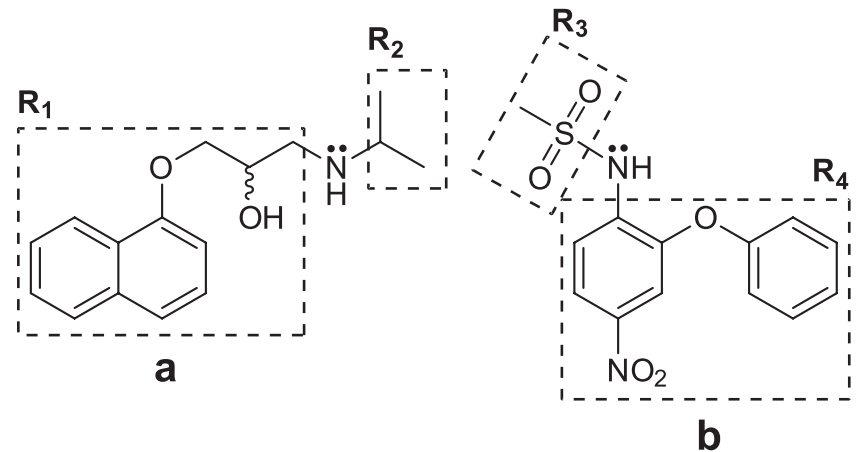

Figura 1. Estruturas químicas do propranolol (a) e da nimesulida (b) destacando os radicais dos grupos amino de cada fármaco

\section{Teoria ácido-base de Brönsted-Lowry}

A teoria protônica de Brönsted-Lowry (1923) é bastante utilizada para explicar as reações ácido-base em sistemas aquosos. Segundo esta teoria, ácido é a espécie química que tende a doar 
prótons $\left(\mathrm{H}^{+}\right)$e base é a espécie química que tende a receber prótons. Neste sentido, cada ácido possuirá sua base conjugada e cada base possuirá seu ácido conjugado e, desta forma, um único próton passa a ser a diferença existente entre ambas as espécies de um mesmo par conjugado. ${ }^{10}$ De acordo com esta teoria, o propranolol assume um caráter de base fraca, em razão do grupo amino secundário, e a nimesulida um caráter de ácido fraco, em função do grupo metanossulfonamida. ${ }^{7,11}$ Diante destas propriedades, a Figura 2 mostra os pares ácido-base conjugados do propranolol e da nimesulida em meio aquoso.

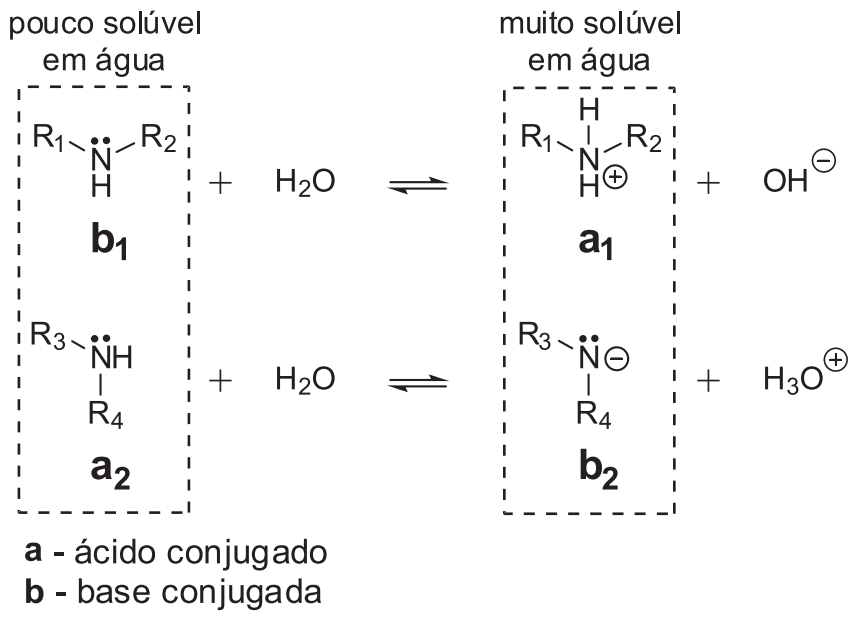

Figura 2. Pares ácido-base conjugados do propranolol $\left(b_{1}\right.$ e $\left.a_{1}\right)$ e da nimesulida $\left(a_{2}\right.$ e $\left.b_{2}\right)$ em meio aquoso

\section{Purificação via extração ácido-base}

A diferença de densidade de carga apresentada pelas moléculas de água a torna um excelente solvente para substâncias polares, como as espécies iônicas. Desta maneira, a solubilidade de moléculas orgânicas neutras em meio aquoso pode ser aumentada quando é possível converter o composto neutro em uma espécie carregada. ${ }^{12} \mathrm{~A}$ extração ácido-base é um procedimento químico de purificação de substâncias ácidas e básicas bastante simples e eficiente e fundamenta-se nas diferenças de solubilidade, em um determinado solvente, das espécies químicas que formam um mesmo par ácido-base conjugado. Em meio aquoso, o propranolol, assim como a nimesulida, sofrem ionização e formam pares ácido-base conjugados (Figura 2) cujas espécies de um mesmo par apresentam solubilidades distintas, sendo as formas neutras dos fármacos pouco solúveis em água e as formas carregadas solúveis neste solvente.

\section{Soluções tampão}

Um tampão é uma solução capaz de amenizar eficientemente alterações de $\mathrm{pH}$ produzidas pela adição de ácidos ou bases em seu seio. Estas soluções são formadas por um ácido fraco e sua respectiva base conjugada ou por uma base fraca e seu respectivo ácido conjugado. Nos tampões, as espécies conjugadas do ácido ou da base fracos estão presentes na solução na forma de sais. ${ }^{10,13}$

As soluções tampão são regidas pela equação de HendersonHasselbalch, a qual, para qualquer tampão constituído de um ácido fraco (HA) e sua respectiva base conjugada $\left(\mathrm{A}^{-}\right)$, esta se torna equivalente à Equação $1 .^{13}$

$$
\begin{gathered}
\mathrm{HA}+\mathrm{H}_{2} \mathrm{O} \rightleftharpoons \mathrm{H}_{3} \mathrm{O}^{+}+\mathrm{A}^{-} \quad \mathrm{K}_{\mathrm{a}} \\
\mathrm{pH}=\mathrm{pK}_{\mathrm{a}}+\frac{\left[\mathrm{A}^{-}\right]}{[\mathrm{HA}]}
\end{gathered}
$$

Já para qualquer tampão constituído de uma base fraca (B:) e seu respectivo ácido conjugado $\left(\mathrm{BH}^{+}\right)$, a equação de HendersonHasselbalch se torna equivalente à Equação 2.

$$
\begin{aligned}
\mathrm{B}:+\mathrm{H}_{2} \mathrm{O} & \rightleftharpoons \mathrm{BH}^{+}+\mathrm{OH}^{-} \quad \mathrm{K}_{\mathrm{b}} \\
\mathrm{pOH} & =\mathrm{pK}_{\mathrm{b}}+\frac{\left[\mathrm{BH}^{+}\right]}{[\mathrm{B}:]}
\end{aligned}
$$

Neste sentido, em qualquer solução tampão o mecanismo tamponante dar-se-á da seguinte forma: o componente básico do tampão (A` ou B:) irá reagir com os prótons oriundos da adição do ácido gerando o componente ácido do tampão $\left(\mathrm{HA}\right.$ ou $\left.\mathrm{BH}^{+}\right)$e amenizando a redução de pH. Já o componente ácido do tampão $\left(\mathrm{HA}\right.$ ou $\left.\mathrm{BH}^{+}\right)$ irá reagir com as hidroxilas oriundas da adição da base gerando o componente básico do tampão (A` ou B:) e amenizando a elevação do $\mathrm{pH} .{ }^{13}$ A partir deste conhecimento os estudantes podem ser estimulados a propor mecanismos reacionais de tamponamento utilizando as estruturas químicas simplificadas da Figura 2 e considerando o efeito da adição de ácido ou base sobre os tampões formados pelos pares ácido-base conjugados dos fármacos em estudo.

\section{Titulação volumétrica ácido-base}

Titulação é o processo onde uma solução-padrão é misturada a uma solução de amostra visando descobrir a concentração de um determinado analito presente na mesma. ${ }^{14} \mathrm{Na}$ titulação volumétrica ácido-base, alíquotas da solução-padrão são geralmente introduzidas através de uma bureta, sendo a reação química que ocorre entre o analito de interesse e a substância da solução padronizada uma reação ácido-base segundo a teoria protônica de Brönsted-Lowry.

Toda curva de titulação associada a uma reação ácido-base possui regiões e pontos característicos fundamentais. Analisando a curva de titulação do ácido maleico $(\mathrm{HOOCC}=\mathrm{CCOOH})$ mostrada na Figura 3 podem-se observar os seguintes pontos: A (ponto de tamponamento máximo da primeira região de tamponamento), B (ponto de equivalência correspondente à neutralização do primeiro próton), $\mathrm{C}$ (ponto de tamponamento máximo da segunda região de tamponamento) e D (ponto de equivalência correspondente à neutralização do segundo próton). A primeira região de tamponamento deve-se à presença simultânea do par conjugado $\mathrm{HOOCC}=\mathrm{CCOOH} /$ $\mathrm{HOOCC}=\mathrm{CCOO}^{-}$no seio da solução, sendo o ponto central A aquele que representa o volume de titulante adicionado, no qual as concentrações de ambas as espécies se igualam. Já a segunda região de tamponamento deve-se à presença simultânea do par conjugado $\mathrm{HOOCC}=\mathrm{CCOO}^{-} /-\mathrm{OOCC}=\mathrm{CCOO}^{-}$no seio da solução, sendo o ponto central $\mathrm{C}$ aquele que representa o volume de titulante adicionado, no qual as concentrações de ambas as espécies se igualam. Assim, durante a titulação do ácido maleico e, considerando a equação de Henderson-Hasselbalch, nos pontos $\mathrm{A}$ e $\mathrm{C}$ o pH da solução do titulado corresponderá respectivamente ao $\mathrm{pK}_{\mathrm{a} 1}(1,9)$ e $\mathrm{pK}_{\mathrm{a} 2}(6,3)$ desta substância. ${ }^{14}$

Na titulação potenciométrica o pH da solução de amostra é monitorado, no decorrer da adição da solução-padrão, com auxílio de um eletrodo de vidro combinado acoplado a um potenciômetro (medidor de $\mathrm{pH}$ ). Desta forma, após ser elaborada a curva de titulação correspondente ao processo, o valor do $\mathrm{pK}_{\mathrm{a}}$ do analito de interesse pode ser obtido a partir da análise das regiões e dos pontos característicos da curva. ${ }^{7}$

\section{Ionização de fármacos em fluidos biológicos}

A constante de ionização de um fármaco, expressa normalmente como $\mathrm{pK}_{\mathrm{a}}$ (independentemente do fármaco ser um ácido ou uma base originalmente), é um parâmetro essencial para a compreensão 


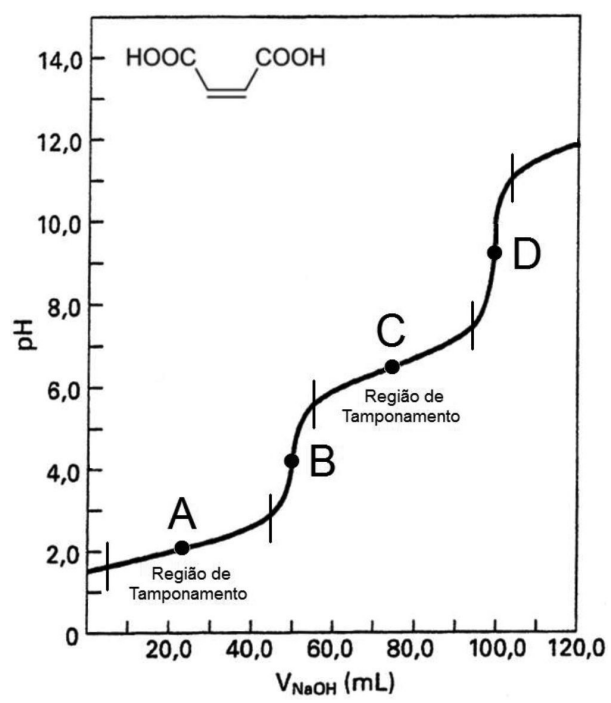

Figura 3. Curva de titulação do ácido maleico delimitando suas principais regiões de tamponamento e zonas de inflexão e mostrando a localização aproximada dos pontos de tamponamento máximo $(A$ e $C)$ e de equivalência (B e D) (Adaptado de Baccan, 2001)

de sua farmacocinética no organismo, principalmente na fase de absorção. ${ }^{15}$ Uma vez que as membranas biológicas tendem a absorver preferencialmente substâncias lipofílicas, os fármacos em sua forma ionizada se tornam mais hidrofílicos e, portanto, menos propensos a atravessarem as duplas camadas lipídicas das membranas. Contudo, os fármacos em sua forma neutra são mais lipofílicos e, com facilidade, podem ser absorvidos.

Em Química Farmacêutica duas relações extremamente importantes são discutidas com os estudantes para que os mesmos passem a compreender melhor em qual $\mathrm{pH}$ de determinado fluido biológico um fármaco terá sua absorção favorecida em função da percentagem de ionização da droga. Para fármacos que atuam como ácidos fracos (nimesulida) a percentagem da droga ionizada em um dado fluido biológico com determinado $\mathrm{pH}$ pode ser calculada a partir da Equação 3. ${ }^{16}$

$$
\% \text { Ionização }=\frac{100}{1+10^{\left(\mathrm{pK}_{\mathrm{a}}-\mathrm{pH}\right)}}
$$

Já para fármacos que atuam como bases fracas (propranolol) a percentagem da droga ionizada em um dado fluido biológico com determinado $\mathrm{pH}$ pode ser calculada a partir da Equação $4 .{ }^{16}$

$$
\% \text { Ionização }=\frac{100}{1+10^{\left(\mathrm{pH}-\mathrm{pK}_{\mathrm{a}}\right)}}
$$

Assim, a partir das Equações 3 e 4, podem-se obter as relações apresentadas no Quadro 1.

Diante destas informações e após a realização dos experimentos para a determinação do $\mathrm{pK}_{\mathrm{a}}$ do propranolol e da nimesulida, os estudantes podem ser estimulados a calcular em que percentagem de ionização o fármaco se encontrará predominantemente considerando o pH normal do estômago ( 2,0) e do intestino delgado ( 8,0), órgãos do sistema digestivo que estas drogas percorrem após a administração oral dos comprimidos.

\section{PARTE EXPERIMENTAL}

\section{Reagentes e equipamentos}

Nos experimentos foram empregados ácido clorídrico (Vetec)
Quadro 1. Percentagem de ionização de fármacos em função do pH de

\begin{tabular}{|c|c|}
\hline 1. Fármacos que a & tuam como ácidos fracos: \\
\hline $\mathrm{pH}=\mathrm{pK}_{\mathrm{a}}$ & $\Rightarrow \quad$ Ionização $=50 \%$ \\
\hline $\mathrm{pH}=\mathrm{pK}_{\mathrm{a}}+1$ & $\Rightarrow \quad$ Ionização $=90 \%$ \\
\hline $\mathrm{pH}=\mathrm{pK}_{\mathrm{a}}+2$ & $\Rightarrow \quad$ Ionização $=99 \%$ \\
\hline $\mathrm{pH}=\mathrm{pK}_{\mathrm{a}}+3$ & $\Rightarrow$ Ionização $=99,9 \%$ \\
\hline 2. Fármacos que a & tuam como bases fracas: \\
\hline $\mathrm{pH}=\mathrm{pK}_{\mathrm{a}}$ & $\Rightarrow \quad$ Ionização $=50 \%$ \\
\hline $\mathrm{pH}=\mathrm{pK}_{\mathrm{a}}-1$ & $\Rightarrow \quad$ Ionização $=90 \%$ \\
\hline $\mathrm{pH}=\mathrm{pK}_{\mathrm{a}}-2$ & $\Rightarrow$ Ionização $=99 \%$ \\
\hline $\mathrm{pH}=\mathrm{pK}_{\mathrm{a}}-3$ & $\Rightarrow \quad$ Ionização $=99,9 \%$ \\
\hline
\end{tabular}
fluido biológico

Adaptado de Cairns, 2008.

e hidróxido de sódio (Vetec), ambos de grau analítico. Acetona PA (Vetec) foi usada sem purificação prévia. Etanol comercial $96{ }^{\circ} \mathrm{GL}$ foi utilizado nos experimentos de cristalização. Água deionizada foi empregada em todos os ensaios. Comprimidos de cloridrato de propranolol $(80 \mathrm{mg})$ e de nimesulida $(100 \mathrm{mg})$ foram adquiridos em farmácias locais pelo professor. Os comprimidos de propranolol apresentavam, além do princípio ativo, os seguintes excipientes: lactose monoidratada, celulose microcristalina, dióxido de silício coloidal, ácido esteárico e estearato de magnésio. Já os comprimidos de nimesulida continham os seguintes excipientes: lactose monoidratada, estearato de magnésio, celulose microcristalina, docusato de sódio, amidoglicolato de sódio, hiprolose e óleo vegetal hidrogenado.

As medidas de $\mathrm{pH}$ foram realizadas utilizando um medidor de pH Tecnopon modelo mPA 210 (potenciômetro), acoplado a um eletrodo de vidro combinado de prata/cloreto de prata. $\mathrm{O}$ aparelho foi calibrado seguindo as recomendações do fabricante do instrumento, sendo utilizadas soluções tampão comerciais em pH 4,00, 7,00 e 10,00 no processo. As titulações potenciométricas foram realizadas à temperatura ambiente.

Os pontos de fusão foram determinados empregando-se um fusiômetro SP Labor, modelo Q340S, equipado com um termômetro de vidro com enchimento de mercúrio (escala $0-300{ }^{\circ} \mathrm{C}$ ). Na falta deste aparelho, os pontos de fusão dos fármacos podem ser medidos usando-se um tubo de Thiele.

\section{Planejamento dos experimentos}

Os experimentos descritos a seguir podem ser realizados em grupos de três estudantes, sendo que cada grupo poderá ficar responsável pela purificação e determinação do $\mathrm{pK}_{\mathrm{a}}$ de um único fármaco (propranolol ou nimesulida). Sugere-se que seja destinada uma aula prática de $2 \mathrm{~h}$ para a realização da purificação e, uma segunda aula prática de $2 \mathrm{~h}$ onde os trios de alunos irão determinar potenciometricamente o $\mathrm{pK}_{\mathrm{a}}$ do fármaco que eles mesmos purificaram. Com o término da segunda aula prática o professor poderá sortear dois grupos, um de cada fármaco, para que os mesmos preparem uma apresentação, de no máximo 15 minutos, descrevendo os experimentos, os resultados e as discussões destas duas aulas práticas para exibi-los a toda a turma na próxima aula da disciplina.

Para os procedimentos de purificação dos fármacos, os estudantes devem conhecer as técnicas de filtração simples, recristalização e determinação de ponto de fusão, já para as determinações de $\mathrm{pK}_{\mathrm{a}}$ se faz necessário conhecimentos de titulação ácido-base e potenciometria. Sugere-se que cada grupo leve e utilize um notebook, com o 
software Microsoft Excel® instalado, para a construção da curva de titulação durante a aula.

\section{Purificação do propranolol via extração ácido-base}

Exatamente 10 comprimidos de cloridrato de propranolol de 80 mg cada (massa total de fármaco $=0,80 \mathrm{~g}$ ) foram macerados em almofariz. O pó foi transferido para um béquer de $250 \mathrm{~mL}$, onde foram adicionados $100 \mathrm{~mL}$ de solução de ácido clorídrico 0,10 $\mathrm{mol} / \mathrm{L}$. A mistura foi agitada e filtrada usando algodão umedecido no funil como meio filtrante. O resíduo sólido foi desprezado (excipientes insolúveis), sendo adicionado sobre o filtrado 100 $\mathrm{mL}$ de solução de hidróxido de sódio $0,20 \mathrm{~mol} / \mathrm{L}$. A suspensão foi agitada e deixada em repouso por 15 minutos. Passado este tempo, a mistura foi filtrada usando algodão umedecido no funil, sendo o sólido espalhado sobre um vidro de relógio e posto para secar em estufa a $50{ }^{\circ} \mathrm{C}$ durante $1 \mathrm{~h}$. O sólido obtido foi pesado (massa de fármaco extraído) e o rendimento percentual da extração calculado utilizando a Equação 5. Uma parte do sólido branco foi purificada através de cristalização, utilizando uma solução de água deionizada/ etanol comercial $96^{\circ} \mathrm{GL} 1: 1$, sendo posteriormente medido o ponto de fusão do sólido puro obtido.

$$
\% \text { Extração }=\frac{\text { Massa de Fármaco Extraído }}{\text { Massa Total de Fármaco }}
$$

\section{Purificação da nimesulida via extração ácido-base}

O procedimento realizado foi semelhante ao da purificação do propranolol, contudo, as seguintes modificações foram realizadas: 1) foram macerados comprimidos de nimesulida de $100 \mathrm{mg}$ cada (massa total de fármaco $=1,00 \mathrm{~g}$ ); 2) a solução de ácido clorídrico $0,10 \mathrm{~mol} / \mathrm{L}$ foi substituída por uma solução de hidróxido de sódio de mesma concentração; e 3) a solução de hidróxido de sódio 0,20 $\mathrm{mol} / \mathrm{L}$ foi substituída por uma solução de ácido clorídrico de mesma concentração.

\section{Titulação potenciométrica do propranolol}

Uma massa de 0,26 g do sólido branco extraído foi pesada em balança analítica. O pó foi transferido para um béquer de $125 \mathrm{~mL}$, sendo adicionados $20,0 \mathrm{~mL}$ de solução de ácido clorídrico $0,10 \mathrm{~mol} / \mathrm{L}$ e 30,0 mL de acetona. A mistura foi agitada, com auxílio de agitador magnético, até a dissolução completa do sólido. Foram introduzidos na solução o eletrodo do medidor de $\mathrm{pH}$ e o sensor de temperatura. Com auxílio de uma micropipeta foram introduzidas alíquotas de $0,25 \mathrm{~mL}$ de solução de hidróxido de sódio $0,20 \mathrm{~mol} / \mathrm{L}$, sendo anotado todos os valores de $\mathrm{pH}$ medidos pelo aparelho após cada adição e estabilização do sinal. A titulação foi realizada até ser adicionado 12,0 $\mathrm{mL}$ da solução de titulante. A curva de titulação correspondente ao processo foi construída plotando-se o volume de titulante gasto em mililitros (eixo $\mathrm{X}$ ) versus o $\mathrm{pH}$ medido (eixo $\mathrm{Y}$ ) usando o software Microsoft Excel囚.

\section{Titulação potenciométrica da nimesulida}

O procedimento realizado foi semelhante ao da titulação do propranolol, contudo, as seguintes modificações foram realizadas: 1) uma massa de $0,31 \mathrm{~g}$ do sólido amarelo pálido extraído foi pesada em balança analítica; 2) a solução de ácido clorídrico $0,10 \mathrm{~mol} / \mathrm{L}$ foi substituída por uma solução de hidróxido de sódio de mesma concentração; e 3) a solução de hidróxido de sódio $0,20 \mathrm{~mol} / \mathrm{L}$ foi substituída por uma solução de ácido clorídrico de mesma concentração.

\section{RESULTADOS E DISCUSSÃO}

\section{Purificação dos fármacos via extração ácido-base}

As extrações ácido-base do propranolol e da nimesulida a partir dos comprimidos basearam-se nas diferenças de solubilidade em meio aquoso dos pares ácido-base conjugados destes fármacos.

A solubilidade do propranolol em meio aquoso ácido deve-se à presença da amina secundária na molécula, a qual atua como uma base fraca de Brönsted-Lowry. Após a protonação da amina forma-se o sal de amina quaternária $\left(\mathrm{R}_{1} \mathrm{R}_{2} \mathrm{NH}_{2}{ }^{+}\right)$que permite a formação de interações intermoleculares do tipo íon-dipolo entre esta substância e a água, além das ligações de hidrogênio já existentes entre este solvente e as funções éter e álcool. São todas estas interações atuando conjuntamente que permitem a solubilização do fármaco em meio aquoso ácido. No processo de extração, a alcalinização do meio desprotona a amina quaternária fazendo com que as interações íon-dipolo deixem de existir, reduzindo a solubilidade do propranolol em água, que consequentemente precipita como molécula neutra.

A solubilidade da nimesulida em meio aquoso alcalino deve-se à presença do grupo metanossulfonamida, o qual atua como um ácido fraco de Brönsted-Lowry. ${ }^{11}$ Após a desprotonação da metanossulfonamida $\left(\mathrm{R}_{1} \mathrm{R}_{2} \mathrm{~N}^{-}\right)$a carga negativa resultante é estabilizada por ressonância, ${ }^{7}$ e a exemplo do que ocorreu com o propranolol, as interações intermoleculares íon-dipolo e ligações de hidrogênio entre o fármaco ionizado e a água são as forças que mantém a nimesulida solubilizada em meio aquoso alcalino. No procedimento de extração, a acidificação do meio protona o grupo metanossulfonamida ionizado fazendo com que as interações íon-dipolo deixem de existir, reduzindo a solubilidade da nimesulida em água, que consequentemente precipita como molécula neutra.

Os rendimentos das extrações ácido-base do propranolol e da nimesulida obtidos por dois alunos de iniciação científica foram aproximadamente $75 \%(0,6 \mathrm{~g})$ e $90 \%$ (0,9 g), respectivamente, da massa esperada de fármaco considerando os 10 comprimidos utilizados nos experimentos. Esta diferença de rendimento pode ser decorrente da maior solubilidade em meio aquoso do propranolol em relação à nimesulida, fato que contribui para a perda de material por solubilização. Além disso, a forma de filtração adotada, algodão umedecido, também pode ter contribuído para estas diferenças de rendimento. $\mathrm{O}$ algodão umedecido foi utilizado como meio filtrante, pois, durante a filtração, os pós-finos dos fármacos rapidamente entopem os poros de um papel de filtro comum, tornando o processo extremamente lento. Em adição, uma tentativa de filtração a vácuo também levou ao mesmo problema.

A confirmação de extração dos fármacos foi realizada através da medida do ponto de fusão dos pós obtidos após purificação por cristalização. O pó branco correspondente ao propranolol demonstrou uma faixa de fusão entre 92 e $97^{\circ} \mathrm{C}$, enquanto que no pó amarelo pálido, correspondente à nimesulida, esta faixa ficou entre $150 \mathrm{e}$ $153{ }^{\circ} \mathrm{C}$. Apesar da proximidade destes valores com os declarados na literatura para o propranolol $\left(\mathrm{PF}=96^{\circ} \mathrm{C}\right)$ e nimesulida $\left(\mathrm{PF}=147^{\circ} \mathrm{C}\right)$, estas largas faixas de fusão podem indicar a presença de impurezas associadas (excipientes inertes dos comprimidos extraídos juntos com os fármacos de interesse). Este fato sugere que o procedimento de cristalização não foi eficiente para a purificação dos fármacos, contudo, como poderá ser visto posteriormente, a presença destes contaminantes não produzirá interferências significativas na determinação potenciométrica do $\mathrm{pK}_{\mathrm{a}}$ do propranolol e da nimesulida. Caso seja desejado, uma forma de melhorar a pureza dos fármacos é realizar uma segunda cristalização. A Tabela 1 resume os resultados obtidos na etapa de extração ácido-base dos fármacos. 
Tabela 1. Resultados da extração ácido-base do propranolol e nimesulida a partir de comprimidos

\begin{tabular}{ccc}
\hline Fármaco & Extração & Faixa de Fusão \\
\hline Propranolol* $^{*}$ & $75 \%$ & $92-97^{\circ} \mathrm{C}$ \\
Nimesulida** $^{*}$ & $90 \%$ & $150-153^{\circ} \mathrm{C}$ \\
\hline
\end{tabular}

$* \mathrm{PF}=96{ }^{\circ} \mathrm{C}$ (Stott et al., 2001). ** $\mathrm{PF}=147^{\circ} \mathrm{C}$ (Shoukri et al., 2009).

Extrações dos fármacos em torno de $75 \%$ e $90 \%$ para o propranolol e nimesulida, respectivamente, indicam que o procedimento ácido-base proposto para a purificação dos fármacos é eficaz, porém, não tão eficiente, dada a contaminação dos fármacos com os excipientes dos comprimidos. É válido salientar que, na realidade, manter uma elevada taxa de extração não é um fator essencial, mas sim, fazer o estudante compreender o processo teórico-prático de purificação via extração ácido-base.

\section{Titulação potenciométrica}

A determinação potenciométrica do $\mathrm{pK}_{\mathrm{a}}$ do propranolol e da nimesulida baseou-se na determinação das mudanças de pH (mensuradas através do medidor de $\mathrm{pH}$ ), à medida que eram adicionadas alíquotas iguais de titulante, até ser atingido o volume estabelecido na parte experimental.

Na curva de titulação potenciométrica do propranolol (Figura 4) é possível verificar duas zonas de inflexão (intervalos dos saltos de $\mathrm{pH}$ ), sendo a primeira delas correspondente à neutralização do excesso de íons hidrônio $\left(\mathrm{H}_{3} \mathrm{O}^{+}\right)$no seio da solução, enquanto que a segunda, um pouco descaracterizada em consequência da fraca acidez e baixa concentração do ácido conjugado, correspondente à neutralização da amina quaternária do fármaco. Com a delimitação da região de tamponamento, decorrente da presença simultânea do par ácido-base conjugado do propranolol na solução de titulado $\left(\mathrm{R}_{1} \mathrm{R}_{2} \mathrm{NH}_{2}{ }^{+} / \mathrm{R}_{1} \mathrm{R}_{2} \mathrm{NH}\right)$, o $\mathrm{pH}$ referente ao ponto central desta região corresponde ao valor do $\mathrm{pK}_{\mathrm{a}}$ do propranolol $(9,30)$, já que foi o ácido conjugado deste fármaco a espécie titulada no ensaio. Este valor é concordante com o apresentado na literatura, entre 9,23 e $9,51,{ }^{17}$ sendo portanto uma prova de que a titulação potenciométrica realizada mostrou-se apropriada para a determinação do valor do $\mathrm{pK}_{\mathrm{a}}$ do propranolol.

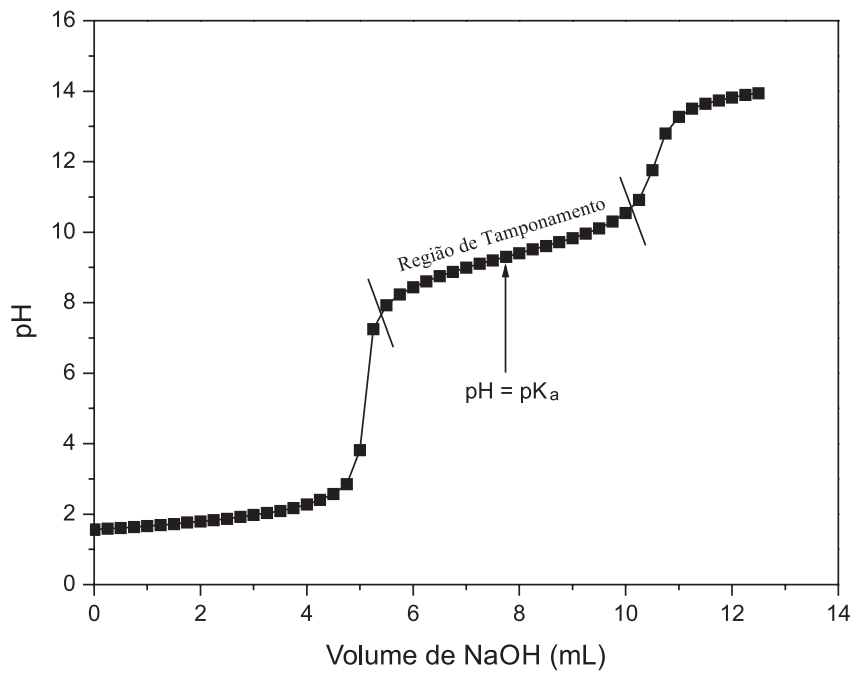

Figura 4. Titulação potenciométrica do ácido conjugado do propranolol mostrando a delimitação da região de tamponamento e a localização de seu ponto de tamponamento máximo $\left(p H=p K_{a}=9,30\right)$
Considerando agora a curva de titulação potenciométrica da nimesulida (Figura 5) é possível verificar novamente duas zonas de inflexão, sendo a primeira delas correspondente à neutralização do excesso de íons hidroxila $\left(\mathrm{OH}^{-}\right)$no seio da solução, e a segunda, correspondente à protonação do grupo metanossulfonamida do fármaco.

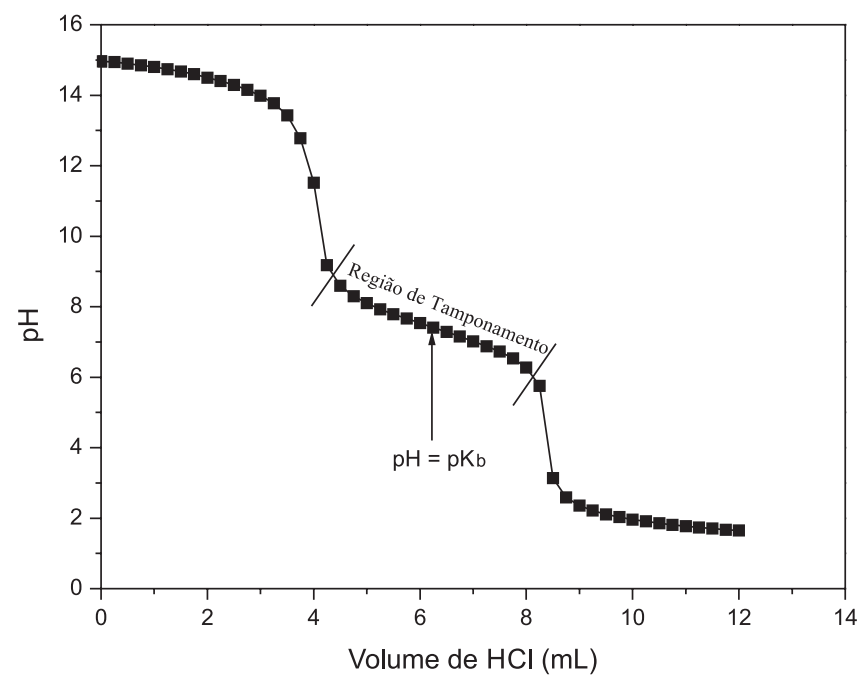

Figura 5. Titulação potenciométrica da base conjugada da nimesulida mostrando a delimitação da região de tamponamento e a localização de seu ponto de tamponamento máximo $\left(\mathrm{pH}=\mathrm{p} K_{b}=7,41\right)$

Com a delimitação da região de tamponamento, decorrente da presença simultânea do par ácido-base conjugado da nimesulida na solução de titulado $\left(\mathrm{R}_{1} \mathrm{R}_{2} \mathrm{~N}^{-} / \mathrm{R}_{1} \mathrm{R}_{2} \mathrm{NH}\right)$, o $\mathrm{pH}$ referente ao ponto central desta região corresponde ao $\mathrm{pK}_{\mathrm{b}}$ da nimesulida $(7,41)$, uma vez que foi a base conjugada deste fármaco a espécie titulada no procedimento. A partir da Equação 6 é possível obter o valor de $\mathrm{pK}_{\mathrm{a}}$ da nimesulida $(6,59)$. Este valor é concordante com o apresentado na literatura, entre 6,46 e $6,56,{ }^{7}$ sendo uma prova de que a titulação potenciométrica realizada, mais uma vez, mostrou-se apropriada para a determinação do valor do $\mathrm{pK}_{\mathrm{a}}$ da nimesulida.

$$
\begin{aligned}
& \mathrm{pK}_{\mathrm{a}}+\mathrm{pK}_{\mathrm{b}}=14 \\
& \mathrm{pK}_{\mathrm{b}}=14-\mathrm{pK}_{\mathrm{a}}
\end{aligned}
$$

A introdução de acetona nos procedimentos de titulação potenciométrica foi necessária para manter o propranolol e a nimesulida solúveis no seio da solução durante todo o processo. A presença deste solvente na proporção inicial estipulada de $60 \%$ (v/v) não interferiu significativamente na determinação do $\mathrm{pK}_{\mathrm{a}}$ dos fármacos em estudo. Além disso, a força iônica do meio também não foi ajustada, mas, dada a proximidade entre os valores teóricos e experimentais das constantes obtidas percebeu-se que o não ajuste deste parâmetro também não produziu erros significativos. A Tabela 2 mostra os valores de $\mathrm{pK}_{\mathrm{a}}$ do propranolol e nimesulida obtidos experimentalmente e a percentagem de ionização destas drogas em

Tabela 2. Valores de $\mathrm{pK}_{\mathrm{a}}$ experimental e percentagem de ionização do propranolol e da nimesulida no $\mathrm{pH}$ estomacal e intestinal

\begin{tabular}{cccc}
\hline Fármaco & $\begin{array}{c}\mathrm{pK}_{\mathrm{a}} \\
\text { Exp. }\end{array}$ & $\begin{array}{c}\text { Ionização } \\
\text { Estômago }^{\mathrm{a}}\end{array}$ & $\begin{array}{c}\text { Ionização } \\
\text { Intestino }^{\mathrm{b}}\end{array}$ \\
\hline Propranolol* $^{*}$ & 9,30 & $99,9 \%$ & $95,2 \%$ \\
Nimesulida** $^{*}$ & 6,59 & $0,003 \%$ & $96,2 \%$ \\
\hline
\end{tabular}

a Estômago ( $\mathrm{pH} \sim 2,0) ;{ }^{\mathrm{b}}$ Intestino $(\mathrm{pH} \sim 8,0) . * \mathrm{pK}_{\mathrm{a}}=9,23-9,51$ (Quigley et al., 1994). ** $\mathrm{pK}_{\mathrm{a}}=6,46-6,56$ (Fallavena e Schapoval, 1997). 
função do pH de fluido biológico do estômago e intestino.

Observando a percentagem de ionização dos fármacos no estômago e intestino na Tabela 2 pode-se dizer que, caso fossem considerados apenas os aspectos químicos, a absorção da nimesulida no estômago seria mais efetiva que a do propranolol, visto que a maior parte deste antiinflamatório estaria na sua forma não ionizada e, portanto, mais lipofílica, enquanto que o propranolol se encontraria predominantemente ionizado. No $\mathrm{pH}$ intestinal, ambos os fármacos seriam absorvidos de forma bastante similar, visto que o grau de ionização dos dois são bem próximos. Porém, cabe salientar que morfologicamente, a mucosa estomacal é especializada na secreção de $\mathrm{HCl}$, e assim, apenas em pequeno grau a absorção de água e de alguns medicamentos é possível..$^{18}$ Desta maneira, pode-se afirmar que, em razão das condições morfofisiológicas do sistema digestivo humano, a nimesulida e o propranolol sofrerão majoritariamente absorção no intestino delgado, que é o órgão de nosso organismo especializado nesta função.

\section{CONCLUSÃO}

O presente trabalho demonstra procedimentos simples e de fácil execução para serem utilizados como aulas práticas de extração ácido-base e de determinação de constante de ionização $\left(\mathrm{pK}_{\mathrm{a}}\right)$, sendo que tais experimentos podem ser aplicados nas disciplinas de Química Orgânica, Química Analítica ou Química Farmacêutica para graduandos de Farmácia, Química ou Engenharia Química. Os procedimentos de extração dos fármacos descritos neste artigo revelaram valores em torno de $75 \%$ e $90 \%$ para o propranolol e nimesulida, respectivamente, indicando que o procedimento ácido-base proposto é eficaz na extração dos fármacos, contudo não é tão eficiente, dado a contaminação dos fármacos com os excipientes dos comprimidos. As titulações potenciométricas realizadas demonstraram valores de $\mathrm{pK}$ do propranolol $(9,30)$ e da nimesulida $(6,59)$ concordantes em relação aos valores descritos na literatura. Neste trabalho, os estudantes também podem verificar a importância de se conhecer o $\mathrm{pK}_{\mathrm{a}}$ de fármacos e as relações existentes entre este parâmetro e as respectivas taxas de ionização e absorção de drogas em fluidos biológicos.

\section{REFERÊNCIAS}

1. Lôbo, S. F.; Quim. Nova 2012, 35, 430.

2. Guimarães, C. C.; Química Nova na Escola 2009, 31, 198

3. Rossi-Rodrigues, B. C.; Oliveira, E. A.; Galembeck, E.; Quim. Nova 2009, 32, 1059.

4. Sartori, E. R.; Barbosa, N. V.; Faria, R. C.; Fatibello-Filho, O.; Ecletica Quim. 2011, 36, 110.

5. Farmacopéia Brasileira 5 ed., Agência Nacional de Vigilância Sanitária: Brasília, 2010.

6. Stott, P. W.; Williams, A. C.; Barry, B. W.; Int. J. Pharm. 2001, 219, 161.

7. Pereira, A. V.; Garabeli, A. A.; Schunemann, G. D.; Borck, P. C.; Quim. Nova 2011, 34, 1656.

8. Ferreira, T. R.; Dissertação de Mestrado, Universidade de Sorocaba, Brasil, 2010.

9. Shoukri, R. A.; Ahmed, I. S.; Shamma, R. N.; Eur. J. Pharm. Biopharm. 2009, 73, 162 .

10. Satyajit D. Sarker, S. D.; Nahar, L. Em Chemistry for Pharmacy Students; John Wiley \& Sons: Chichester, 2007, cap. 1.

11. Fallavena, P. R. B.; Schapoval, E. E. S.; Int. J. Pharm. 1997, 158, 109.

12. Lehninger, A. L.; Nelson, D. L.; Cox, M. M.; Em Lehninger Principles of Biochemistry 4 ed.; W. H. Freeman: New York, 2005, cap. 2.

13. Fiorucci, A. R.; Soares, M. H. F. B.; Cavalheiro, É. T. G.; Química Nova na Escola 2001, 13, 18.

14. Baccan, N.; Andrade, J. C.; Godinho, O. E. S.; Barone, J. S.; Química Analítica Quantitativa Elementar 3 ed, Edgard Blucher: Campinas, 2001, cap. 3.

15. Şanli, N.; Şanli, S.; Özkan, G.; Denizli, A.; J. Braz. Chem. Soc. 2010 , 21, 1952.

16. Cairns; D.; Em Essentials of Pharmaceutical Chemistry 3 ed.; Pharmaceutical Press: London, 2008, cap.1.

17. Quigley, J. M.; Jordan, C. G. M.; Timoney, R. F.; Int. J. Pharm. 1994, 101,145 .

18. Di Dio, L. J. A.; Tratado de Anatomia Sistêmica Aplicada - v.2, 2 ed., Editora Atheneu: São Paulo, 2002, cap. 13. 